\title{
Journal Anniversary Symposium 2010 Dedicated to Europe/Japan Stroke Research Cooperation
}

\author{
M.G. Hennerici, Germany; K. Minematsu, Japan \\ Contributors: \\ D. Leys, France; K. Toyoda, Japan; S. Uchiyama, Japan; H.-C. Diener, Germany
}

\section{Introduction}

The journal Cerebrovascular Diseases, founded 20 years ago as a European organ publishing articles from clinical stroke research and now the second leading international journal covering all aspects of basic, experimental and clinical research of cerebrovascular diseases worldwide, has seen a more than $50 \%$ increase in submissions of manuscripts from Asia and particularly Japan in recent years. High-quality treatment of acute stroke patients in specialized stroke units and comprehensive stroke centers as well as modern neuroimaging techniques have been established in Japan and Europe despite different epidemiological, lifestyle and risk factor patterns, treatment concepts and management customs. Pharmacotherapy is also challenging: Japan and Europe have different health authorities, approval regulations and medical infrastructures. However, there are a lot of similarities in acute stroke management, prevention strategies and research perspectives, stimulating a strong cooperation with increasing exchange of data and ideas among scientists and clinicians.

On the occasion of the 20th anniversary of Cerebrovascular Diseases, a special symposium was organized during the 19th European Stroke Conference 2010 in Barcelona/Spain presenting some recent achievements of European and Japanese stroke research (fig. 1). The focus was on acute stroke management and stroke prevention. Speakers talked about acute stroke management with re-

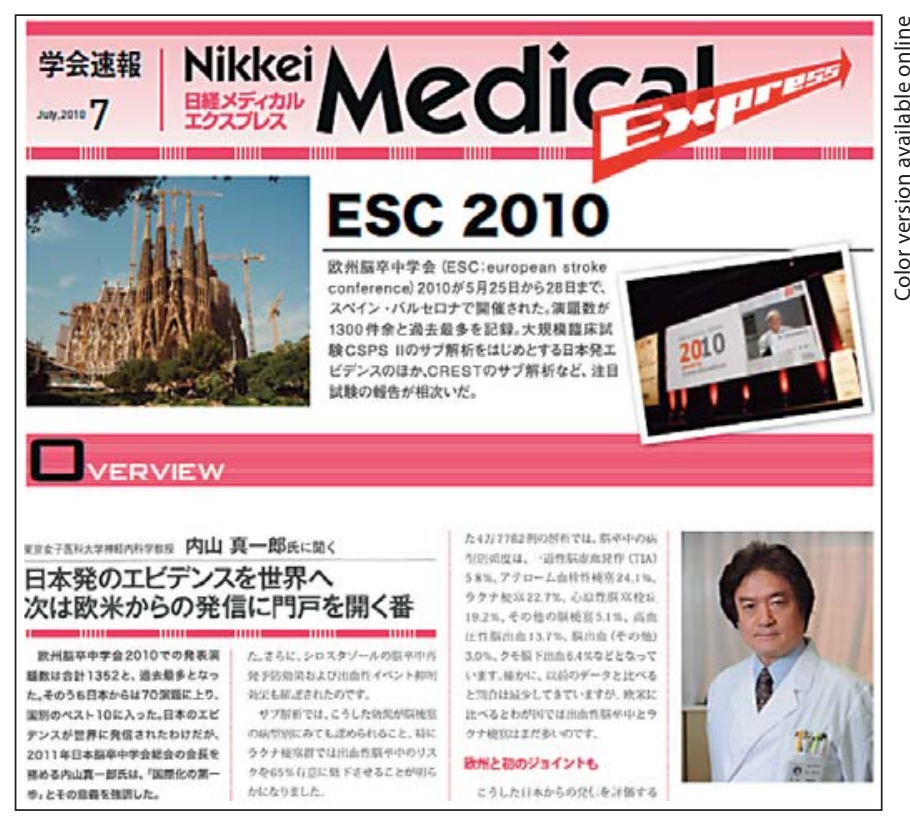

Fig. 1. Report on the Cerebrovascular Diseases Europe/Japan Stroke Research Cooperation Symposium published in Japan Nikkei Medical Express in July 2010 (reprinted with kind permission).

spect to the hospital facilities, availability of therapeutics and ongoing studies as well as on the stroke prevention using antiplatelet and antithrombotic agents in Japan and Europe, respectively.

\section{KARGER}

Fax +41613061234 E-Mail karger@karger.ch www.karger.com
(C) 2010 S. Karger AG, Base

$1015-9770 / 10 / 0306-0537 \$ 26.00 / 0$ 


\section{Acute Stroke Management in Europe - D. Leys (France)}

It has been shown that stroke unit care reduces death and dependency; however, only sparse reports of evidence-based data exist on which facilities really make the difference. A European survey was conducted in 2006 to investigate the structure and instruments used in many centers, which claimed to be able to treat stroke. Unfortunately, different from what might have been anticipated, several centers fell short of the expert opinion of what a primary stroke center, a comprehensive stroke center or any general hospital ward minimally requires for treating acute stroke [1]. Indeed, more than $50 \%$ of hospitals randomly surveyed did not have any facility to perform intravenous tissue plasminogen activator therapy [recombinant tissue (rt-PA) or tissue plasminogen activator, e.g. alteplase], which is still the only approved specific treatment of acute stroke patients.

Although the results were not particularly flattering for Europe (particularly considering the high healthcare standards in many countries) and only reflected the facilities available (i.e. not what was actually used in treating patients), the work provides evidence to arm hospitals when approaching government and health authorities for further funding and planning. There have been new regulations since 2005 in several countries, so it is expected that EU and EU zone hospitals are improving. Audits on care and detailed data at the national and local levels, adequate quality markers of stroke units and their implementation as well as an EU-wide accreditation process are clearly the next steps.

\section{Acute Stroke Management in Japan: Insights from the SAMURAI Study - K. Toyoda (Japan)}

The SAMURAI (Stroke Acute Management with Urgent Risk Factor Assessment and Improvement) rt-PA Registry was a retrospective multicenter observational study by 10 stroke centers across Japan. Six hundred patients with ischemic stroke who received low-dose rt-PA using $0.6 \mathrm{mg} / \mathrm{kg}$ i.v. alteplase (different from the $0.9 \mathrm{mg} /$ $\mathrm{kg}$ alteplase used in Europe) were registered. The results were differentiated from the Safe Implementation of Thrombolysis in Stroke Monitoring Study (SITS-MOST), a similar prospective worldwide registry [2].

In SAMURAI, 33\% of overall patients had a modified Rankin scale (mRS) of $0-1$ at 3 months, and $41 \%$ had a favorable outcome. The frequency of patients who died within 3 months was $7 \%$. Thus, the general efficacy and safety of this low-dose rt-PA regimen were similar to those of SITS-MOST and other surveys. A possible disadvantage of low-dose rt-PA might have been incomplete recanalization. A recent Japanese trial, the Japan Alteplase Clinical Trial 2, has an answer for this question [3]. In 58 patients with middle cerebral artery (MCA) occlusion on magnetic resonance angiography (MRA) and treated with alteplase at $0.6 \mathrm{mg} / \mathrm{kg}$, approximately $50 \%$ of the occluded MCAs were recanalized $6 \mathrm{~h}$ after the onset, and $70 \%$ were recanalized $24 \mathrm{~h}$ later. After multivariate analysis, recanalization at $6 \mathrm{~h}$ as well as at $24 \mathrm{~h}$ was independently associated with mRS $0-1$ at 3 months.

Both examples show that different treatment regimens - deriving from different treatment recommendations - may finally result in similar outcomes but different substudy results. Joint insight of given data and different concepts of management may be used for future cooperation, e.g. diffusion-weighted imaging and magnetic resonance angiography monitoring for predicting outcomes after rt-PA.

\section{Antithrombotic Therapy for Stroke Patients in Japan - S. Uchiyama (Japan)}

Aspirin is the most widely used antiplatelet agent in Japan; however, its efficacy is modest at best. Clopidogrel has become recently approved in Japan (since 2006). Dipyridamole has not been approved in Japan, although it is used in combination with aspirin in the EU and USA. Several complimentary studies are ongoing or have been reported recently addressing this issue.

The limited efficacy of aspirin is argued with the term 'aspirin resistance'. There could be many factors for aspirin resistance, with one possible factor being the genetic profile. The Profile and Genetic Factors of Aspirin Resistance study has been conducted to investigate genetic factors for aspirin resistance, and the final results will be presented during the World Congress of Thrombosis and Hemostasis, next July in Kyoto.

According to the results of the Prevention Regiment for Effectively Avoiding Second Strokes study, stroke recurrence was comparable between patients on extendedrelease dipyridamole plus aspirin versus clopidogrel, but intracerebral hemorrhage was more frequent in patients on dipyridamole plus aspirin than clopidogrel. The Japanese Aggrenox Stroke Prevention study, comparing extended-release dipyridamole plus aspirin versus aspirin alone, has recently been completed; the final results will 
be presented at the World Stroke Congress in Seoul, Korea, in October 2010.

Combined analysis of 2 phase III randomized controlled trials for the direct comparison of ticlopidine versus clopidogrel in Japanese stroke patients showed severe liver dysfunction, neutropenia and thrombocytopenia to be $40 \%$ less frequent with clopidogrel than with ticlopidine. However, an issue remains with clopidogrel resistance. Studies are looking at the genetic effects in resistance mechanisms, particularly in patients who are carriers of polymorphisms of CYP2C19. This polymorphism is more frequent in Japanese (and Asian) than in Caucasian populations.

A meta-analysis of the placebo-controlled randomized trials of cilostazol in patients with atherothrombosis showed a substantial reduction of cerebrovascular events without increasing bleeding risk. The results of the Cilostazol Stroke Prevention Study II suggested that cilostazol was more effective and safer than aspirin. Final results were reported during the European Stroke Conference in Barcelona in 2010 [4].

\section{Antithrombotic Therapy for Stroke Patients in Europe - H.-C. Diener (Germany)}

Focusing on primary prevention in patients with atrial fibrillation (AF) from a EU perspective, H.-C. Diener presented data on warfarin monotherapy, combinations with aspirin and the new antithrombotic agents such as dabigatran.
Several new thrombin antagonists have already shown excellent efficacy and safety very likely superior to warfarin [5] while others are on the horizon; thus, several new preventive therapy options will become available in patients with AF facilitating not only easier management and compliance of preventive treatment, but also offering excellent safety and better efficacy. This is barely needed as both aspirin alone and the use of clopidogrel and aspirin in combination are less effective than warfarin monotherapy in AF $[6,7]$.

Interestingly, from a European perspective 'aspirin resistance' turns out to be mostly a noncompliance issue. When compliant patients are tested for platelet aggregation, the results are unrealistically changing from day to day, leading one to question the methodology of these results. The concept of 'aspirin resistance' in European patients is questionable at best, and the very few studies of genetic effects do not support this concept. The current expert opinion is that compliance should be re-enforced with the patient, and the treatment should be maintained.

\section{Acknowledgements}

We thank the active participants of the Anniversary Symposium at the European Stroke Conference and the audience for their insightful comments. We also thank Tania Khan, $\mathrm{PhD}$, for editorial assistance, provided by the journal Cerebrovascular Diseases (S. Karger AG, Basel).

\section{References}

1 Leys D, Ringelstein EB, Kaste M, Hacke W: European Stroke Initiative Executive Committee: the main components of stroke unit care: results of a European expert survey. Cerebrovasc Dis 2007;23:344-352.

-2 Toyoda K, Koga M, Naganuma M, Shiokawa Y, Nakagawara J, Furui E, Kimura K, Yamagami $\mathrm{H}$, Okada Y, Hasegawa Y, Kario K, Okuda S, Nishiyama K, Minematsu K; Stroke Acute Management with Urgent Risk-factor Assessment and Improvement (SAMURAI) Study Investigators: Routine use of intravenous low-dose rt-PA in Japanese patients: general outcomes and prognostic factors from the SAMURAI register. Stroke 2009; 40:3591-3595.

\footnotetext{
3 Mori E, Minematsu K, Nakagawara J, Yamaguchi T, Sasaki M, Hirano T, J-ACT II Group: Effects of $0.6 \mathrm{mg} / \mathrm{kg}$ intravenous alteplase on vascular and clinical outcomes in middle cerebral artery occlusion: Japan Alteplase Clinical Trial II (J-ACT II). Stroke 2010;41: 461-465.

4 Uchiyama S, for the CSPS II Group: The main results and subgroup analyses of Cilostazol Stroke Prevention Study II (CSPS II). Cerebrovasc Dis 2010;29(suppl 2):11-12.

$\checkmark 5$ Connolly SJ, Ezekowitz MD, Yusuf S, Eikelboom J, Oldgren J, Parekh A, et al: Dabigatran versus warfarin in patients with atrial fibrillation. N Engl J Med 2009;361:1139_ 1151.
}

\footnotetext{
6 ACTIVE Writing Group on behalf of the ACTIVE Investigators, Connolly S, Pogue J, Hart R, Pfeffer M, Hohnloser S, et al: Clopidogrel plus aspirin versus oral anticoagulation for atrial fibrillation in the Atrial Fibrillation Clopidogrel Trial with Irbesartan for Prevention of Vascular Events (ACTIVE W): a randomised controlled trial. Lancet 2006; 367:1903-1912.

7 Connolly SJ, Pogue J, Hart RG, Hohnloser SH, Pfeffer M, Chrolavicius S, et al: Effect of clopidogrel added to aspirin in patients with atrial fibrillation. N Engl J Med 2009;360: 2066-2078
} 